\title{
O valor da visita em uma ação de visitação: turismo de base comunitária, dinheiro e filosofia política sertaneja
}

The value of visiting in a visitation action: community-based tourism, money and political philosophy in the Sertão

\section{Ana Carneiro Cerqueira}

\section{(2) OpenEdition Journals}

\section{Edição electrónica}

URL: http://journals.openedition.org/aa/3960

DOI: $10.4000 /$ aa.3960

ISSN: 2357-738X

\section{Editora}

Programa de Pós-Graduação em Antropologia Social (UnB)

\section{Edição impressa}

Data de publição: 1 dezembro 2019

Paginação: 281-304

ISSN: 0102-4302

\section{Refêrencia eletrónica}

Ana Carneiro Cerqueira, «O valor da visita em uma ação de visitação: turismo de base comunitária, dinheiro e filosofia política sertaneja», Anuário Antropológico [Online], v.44 n.2 | 2019, posto online no dia 02 dezembro 2019, consultado o 27 abril 2021. URL: http://journals.openedition.org/aa/3960 ; DOI: https://doi.org/10.4000/aa.3960

\section{@(@) $\Theta \Theta$}

Anuário Antropológico is licensed under a Creative Commons Atribuição-Uso Não-Comercial-Proibição de realização de Obras Derivadas 4.0 International. 


\title{
O valor da visita em uma ação de visitação: turismo de base comunitária, dinheiro e filosofia política sertaneja
}

\section{The value of visiting in a visitation action: community-based tourism, money and political philosophy in the Sertão}

\author{
Ana Carneiro Cerqueira \\ Universidade Federal do Sul da Bahia
}

Analiso aqui dados etnográficos coletados por mim em duas situações distin$\operatorname{tas}^{1}$. Em uma delas, trabalhei como consultora de uma ação de visitação promovida em 2015 pelo Projeto de Turismo Ecocultural de Base Comunitária (doravante, Projeto TBC) do Território Mosaico Sertão Veredas - Peruaçu (doravante, Mosaico). A outra experiência consistiu em 16 meses de trabalho de campo etnográfico entre 2006 e 2009, junto ao Povo dos Buracos, em área abrangida pelo mesmo projeto ${ }^{2}$. Em função das indagações instigadas por um episódio ocorrido durante a ação de visitação, recupero, no diário de campo, dados coletados anteriormente sobre a vida diária dos buraqueiros ${ }^{3}$. O episódio ocorreu durante uma atividade na qual os participantes deveriam apresentar suas considerações sobre os pontos positivos e negativos da ação recém executada. Foi então que uma controvérsia surgiu a respeito da cobrança em dinheiro aos turistas que fossem visitar as casas dos agricultores familiares.

De um lado, as coordenadoras da atividade defendiam precificar a recepção aos turistas, com o propósito de geração de renda; de outro, os futuros anfitriões julgavam que, em certos causos, a cobrança em dinheiro seria inadmissível. Que espécie de relação outra com os turistas poderia ser desejada por eles se não a da troca mercantil? É sobre essa outra modalidade da relação que proponho investigar. Não se trata de estabelecer uma externalidade entre dois mundos supostamente opostos: um dos laços comunitários e não capitalistas; outro do mercado e da exploração. Tal abordagem já foi suficientemente refutada (por exemplo, Martins, 1996; Musumeci, 1988). O que nos interessa, através da controvérsia sobre o valor da visita, é 
indagar sobre como certas composições relacionais assumem maneiras específicas de lidar com o dinheiro. Por este caminho, ao final do artigo exploraremos a ideia de uma "filosofia política” presente nas práticas sertanejas de visita.

\section{Geração de renda, valorização cultural, riqueza ambiental, catira e o diabo}

À margem esquerda do Médio Rio São Francisco, o Território Mosaico Sertão Veredas - Peruaçu ${ }^{4}$ integra municípios do norte de Minas Gerais e sudoeste da Bahia, incluindo duas terras indígenas, diversos povos de agricultores familiares (alguns em processo de reconhecimento como comunidades quilombolas) e 14 unidades de conservação ${ }^{5}$. O Mosaico resultou dos esforços de um grupo de associações, organizações civis e órgãos gestores ambientais que, atuantes na região, elaboraram entre 2007 e 2008 um Plano de Desenvolvimento Territorial de Base Conservacionista no qual já se previa a implantação de um projeto de turismo de base comunitária ${ }^{6}$. O Projeto TBC iniciou-se em 2010, através de um edital do Fundo Socioambiental da Caixa Econômica Federal, em parceria com o Ministério do Meio Ambiente, e executado pelo Instituto Rosa e Sertão, organização não governamental com sede em Chapada Gaúcha (município no qual se situa o Povo dos Buracos).

Todo um novo vocabulário passa a circular nesse contexto. Nesse turismo diferenciado, o que se oferece é uma vivência cultural. O "guia turístico" é substituído pelo termo condutor ambiental; o "hoteleiro" cede lugar aos anfitriões; e estes são definidos como parceiros locais (ou simplesmente parceiros) - ao mesmo tempo executores e beneficiários da geração de renda prevista pelo projeto. $\mathrm{O}$ intuito era fomentar uma economia com base no Cerrado em pé, fazendo frente à expansão da fronteira do agronegócio na região.

$\mathrm{Na}$ ação de visitação, quinze moradores do polo oeste do Mosaico viajavam para visitar os moradores do polo leste. Em seguida seria feito o movimento inverso: os parceiros de cada polo haveriam de trocar as posições de visitantes-turistas e de parceiros-anfitriões. Os viajantes da ação experimentavam assim estar na pele de turistas uma experiência efetivamente inédita para eles - e assim entenderiam as demandas dos que futuramente visitariam suas casas. Os parceiros presentes naquela viagem já haviam participado de outras ações do Projeto TBC, que naquele momento estava prestes a ser concluído.

O Mosaico, entendido como um território, deveria explorar sua própria identidade cultural, destacavam as coordenadoras da ação. A riqueza cultural era então asso- 
ciada à riqueza ambiental do cerrado, integrando comunidades tradicionais e unidades de conservação. Assim as casas dos agricultores - com paredes de adobe e telhados de palha de buriti - estavam sendo valorizadas e deveriam ser preparadas para se tornar pontos receptivos ao turista, criando-se, nos termos do projeto, uma rede de serviços nos pressupostos de um turismo não predatório, cujos objetivos principais são a valorização da cultura local e a geração de renda para as comunidades tradicionais (Instituto Rosa e Sertão, s/d). Um vocabulário que reúne riqueza ambiental, valorização cultural e geração de renda traz o tema do dinheiro como pista etnográfica interessante; não à toa tornou-se objeto da controvérsia que resultou no episódio já mencionado ${ }^{7}$.

Ao longo da ação de visitação, eu questionava os parceiros sobre suas motivações em participar do projeto e eles de imediato discorriam sobre expectativas quanto ao dinheirinho, à rendinha extra a ser gerada pelas visitas de gente de fora. O que teria então gerado a afirmação de recusa à cobrança em dinheiro a certos turistas? Mais recentemente, cerca de três anos depois daquela ação de visitação, estive com a diretora executiva da ONG responsável pelo Projeto TBC e conversamos sobre o episódio. Ela, filha de pai ribeirinho do São Francisco e moradora na região desde a adolescência, considera haver, entre as pessoas da região, uma demonização de tudo o que gera dinheiro. Suas palavras me remeteram à análise de Michael Taussig (2010 [1980]) sobre o significado social do diabo nos canaviais do agronegócio colombiano. A profusão de estórias de pacto com o diabo entre os camponeses daquela região evidenciava, segundo o autor, "uma acusação contra o sistema econômico que força os homens a trocar suas almas pelo poder destrutivo da mercadoria” (Taussig, 2010 [1980], p. 18).

Taussig amplifica as implicações desta afirmação e escapa à polarização simplista entre o mercado e a tradição. Ao apresentar as suspeitas de pacto com o diabo - voltadas a indivíduos cuja produtividade nos canaviais ultrapassam os parâmetros do bom senso -, o material etnográfico de Taussig (Idem, p. 143-146) revela, sobretudo, uma relação de desconfiança em relação a uma certa relação com o dinheiro. O alto valor gerado pelo trabalho de um camponês pactuado com o diabo deveria ser gasto com consumo de luxo; nunca para investir em nova lavoura, gerar mais renda, capitalizar. A maneira de gastar o dinheiro recebido pela produtividade excessiva revelava, em suma, um dinheiro amaldiçoado, oriundo da submissão ao trabalho humilhante, o que por sua vez gerava a suspeita do pacto. Tal evidência não pode nos levar a inferir que o investimento agrícola modernizante fosse em si recusado pelos camponeses colombianos, mas sim que os efeitos da modernização na relação com a terra eram alvo de preocu- 
pação; o que estava em jogo eram "significados contraditórios e interconectados" do fetiche da mercadoria (Idem, p. 18). Como observou Luzimar Pereira sobre histórias de pactos com o diabo feitos por violeiros nortemineiros (2018, p. 25-34), a "fama" trazida a estes supostos pactuantes tem como elemento principal, “o diabo da dúvida”.

Também parece contraditório que, nos Buracos, os mesmos agricultores agora contrários à cobrança já haviam antes se mostrado satisfeitos em receber um valor em dinheiro dos turistas. Havia mesmo uma tabela informal de preços preestabelecidos entre as casas, em função do número de frangos mortos e cozinhados, na qual as donas de casa baseavam sua cobrança. Em minha estadia com os buraqueiros, vi que o dinheiro era preocupação constantemente explicitada nas conversas rotineiras e em discussões mais graves dentro da própria família. O tema tensionava relações dentro e fora de casa, levando a conversa aos cálculos, balanços, queixas e buscas por equivalências que sanassem dívidas financeiras, seja entre parentes ou diante de injustiças nas transações com comerciantes ou governantes.

A catira, por exemplo, troca de bens baseada em uma rede de relações de parentesco e/ ou amizade, mostrou-se uma fonte inesgotável de causos que acionam equivalências entre os bens trocados e os valores em dinheiro. Ainda hoje, tudo o que é trocado por meio da catira (seja uma panela ou um cavalo) é precificado em função de um cálculo complexo, articulando valor de uso, valor de mercado e narrativas sobre a origem e a história de circulação do objeto trocado. Todos fazem catira, mas há os chamados catireiros, pessoas especialmente ativas nesta prática, capazes de acionar uma ampla rede de conhecimento sobre o circuito traçado pelas coisas trocadas (cf. Ribeiro; Galizoni, 2007).

Os causos sobre catiras muitas vezes tematizam as vicissitudes financeiras vividas pela família do catireiro. Este não raro assume uma figura cômica, algo à maneira dos tricksters (Basso, 1987; Babcock-Abrahams, 1975), o que evidencia como é delicado o tema do dinheiro. Neste sentido, tive dificuldades quando quis estabelecer uma quantia mensal a ser paga a D. Rosa, ao morar por meses em sua casa, nos Buracos. Ela recebia de mim o dinheiro mas reclamava que não era em troca de dinheiro que eu estava ali.

\section{Quem era esse povo de viajantes?}

O povo dos Buracos surgiu na antiga Fazenda dos Buracas, comprada pelo bisavô de Paulo. Hoje, cerca de 40 casas ligadas por laços consanguíneos e/ou de afinidade espraiam-se em conexão com outras casas, seja nos povos vizinhos, seja na sede 
municipal de Chapada Gaúcha ou nas capitais mais distantes, sobretudo Brasília e São Paulo. No primeiro caso, aparentados sem direito à herança nos Buracos foram habitando outras terras; no segundo, aqueles que saíram para caçar a sorte na cidade mantêm o desejo sempre renovado de visitar as casas dos parentes nos Buracos. Essa dinâmica de espraiamento contínuo integra o próprio modo de existência de povos que vão gerando outros povoamentos vizinhos ou novos aglomerados internos a partir dos casamentos e novas ramificações. O mesmo ocorre com famílias de outros povos, que se misturam aos buraqueiros. Espraiam-se mas se mantêm conectados por movimentos pessoais e familiares entre as casas, traçando e retraçando um território físico e existencial. Podemos dizer, no sentido deleuzeguattariano, que esses povos são "multiplicidades” (Deleuze e Guattari, 1968, p. 236), constituindo-se, a um só tempo, como união e diferenciação contínuas, externa e internamente (cf. Carneiro, 2014; 2015a; 2017).

Cada povoamento constitui-se quase inteiramente por agricultores familiares (às vezes com atividades complementares). São pequenos herdeiros ou posseiros, cujos lotes variam entre cerca de sete a cem hectares, por família, embora não passe de meio hectare a produção de terra cultivada (sobretudo mandioca, feijão, milho e abóbora). São gente da roça, como eles próprios se reconhecem, ou sertanejos de comunidades tradicionais, como dizem os turistas que chegam por lá.

Do total de 15 parceiros de diversas idades e comunidades do oeste do Mosaico, o grupo de viajantes que partia do oeste do Mosaico para visitar a porção leste reunia três buraqueiros. Entre eles, Paulo Gomes, filho de agricultores, praticamente cego devido a um problema congênito. O trabalho na roça nunca lhe foi possível - ou nunca desejável, difícil saber. O que gosta é das mexidas de projeto, diz ele. Eu gosto é de mexer com meio ambiente, cultura... Já comandou um programa na rádio comunitária, dedicado ao cantor Amado Batista; já se candidatou a vereador (sem sucesso, pois, como dizem seus parentes: mexer com política é coisa de rico!). Não fez dinheiro com nenhum desses trabalhos, vive da aposentadoria por invalidez rural, morando algumas épocas do ano na casa dos pais nos Buracos e, noutras fases, na casa que seus pais possuem na vila de Chapada Gaúcha, sede municipal situada a cerca de 10 quilômetros dos Buracos. Paulo também já morou por dois anos na cidade de São Paulo, na casa de uma irmã que se mudara para a capital.

Os outros dois buraqueiros da viagem eram Valéria e Albergs, um casal de ex-operários da periferia paulista, mas nascidos na roça, no interior dos estados de São Paulo (ele) e Bahia (ela). Deixaram a vida urbana para morar na vila de Chapada 
Gaúcha, onde conquistaram um bom padrão de consumo, construíram sua casa própria e compraram duas outras nos Buracos. Hoje, duas casas antes pertencentes aos parentes de Paulo servem, uma, ao casal (para férias e finais de semana), a outra, como moradia do pai de Albergs, agricultor. Essas eram, na época de minha pesquisa, as duas únicas casas dos Buracos pertencentes a gente de fora.

Sem interesse no trabalho na agricultura, Paulo Gomes é visto como diferente por seus primos moradores dos Buracos; Valéria e Albergs, por sua vez, são considerados buraqueiros, mas seus vizinhos os consideram gente de fora. A descrição desses três personagens, enfim, não diria muito sobre os Buracos nem sobre o conjunto dos viajantes da ação de visitação a não ser pela característica movimentação constitutiva das trajetórias pessoais e familiares no norte de Minas Gerais.

Assim também se constituem os percursos de Damiana, Diana e Daiana. Articulando diversas ações, o Projeto TBC era tocado pelas três irmãs, como todos os projetos do Instituto Rosa e Sertão. O pai, nascido e criado em uma comunidade ribeirinha à margem direita do Médio Rio São Francisco, migrara para Osasco (São Paulo), onde conhecera sua futura esposa, vinda no sul de Minas Gerais. Ele operário, ela empregada doméstica, casaram-se em Osasco e lá tiveram as três filhas. Quando estas eram pré-adolescentes, a família veio para a cidade de São Francisco, onde moraram até o início dos anos 2000, quando Damiana, formada em pedagogia, passou em um concurso para a rede de ensino municipal de Chapada Gaúcha, puxando para lá o resto da família.

Por fim, o grupo de viajantes daquela ação de visitação era formado ainda por pessoas contratadas como consultoras: além de mim, uma fotógrafa profissional e duas turismólogas que coordenavam a ação. Vínhamos da cidade grande (Rio de Janeiro e Belo Horizonte) e éramos pagas para transformar aquela experiência de viagem em produtos culturais ${ }^{8}$, ou, como diria Félix Guattari (1996, p. 11-25), para transformar a "cultura alma-coletiva" em "cultura mercadoria". Ora, no Projeto TBC, meu antigo interesse em etnografar modos cotidianos da casa e da cozinha buraqueira ativava linhas de força agora determinantes no agenciamento modernizante que proponho descrever aqui.

Meu posicionamento, múltiplo e inevitavelmente dúbio, junto aos movimentos que marcam as diferentes trajetórias dos viajantes, remetem-nos aos efeitos inesperados das chamadas políticas de participação social nas quais o Projeto TBC se enquadrava, trazendo à cena, como pano de fundo, as implicações indesejadas da aplicabilidade da antropologia fora das práticas acadêmicas ${ }^{9}$. Embora o tema venha sendo 
evitado pela produção antropológica mais reputada, há brechas por onde aparece, sorrateiro. Uma delas é a tematização das (im)possibilidades de comunicação entre as diferentes (quiçá inconciliáveis) perspectivas postas em relação a partir dos contextos de tais políticas.

Francisco Pazzarelli (2016), ao etnografar a execução de um projeto de construção de “cozinhas econômicas” em uma comunidade de Jujuy, interior da Argentina, mostra como o plano se equivocou sobre aquilo que era seu próprio propósito: a melhoria da saúde da população atrelada ao fim da fumaça dos fogões à lenha, elemento essencial à saúde das relações comunitárias. Mais do que uma simples falha de comunicação, as diferentes perspectivas encarnavam, na avaliação do autor, uma “equivocação", no sentido elaborado por Eduardo Viveiros de Castro (2004): não eram formas diferentes de "ver o mundo", mas sim uma diferença entre os próprios mundos postos em relação (Viveiros de Castro, 2004, p. 11 apud Pazzarelli, 2016). Daniela Perutti (2018) também explorou este conceito ao investigar, a partir de sua etnografia na comunidade quilombola de Família Magalhães, em Goiás, "a incidência local de políticas públicas relativas a ou aplicadas sobre casas, bem como os efeitos de sua implementação, tendo em vista sentidos específicos que lhe são dados" (Idem, p. 46). Ao articular diferentes narrativas envolvendo agentes do governo, quilombolas e a própria antropóloga, ela mostra como as políticas estatais se articulam ou se afastam do modo de ser "amigueiro" que constitui aquela comunidade. Em ambos os trabalhos, não se trata de observar, nos casos estudados, como a “equivocação" seria capaz de dar resposta empírica ao problema do desentendimento entre os sujeitos observados. Diversamente, tal conceito mostra rendimento quando nos leva a perceber e questionar nossos próprios pressupostos analíticos - no caso aqui, os de que podemos definir os "sujeitos" das diferentes perspectivas antes de nos engajarmos na relação de troca comunicativa.

\section{O valor da visita: composições relacionais da festa e da política}

As relações definidoras do Povo dos Buracos evidenciavam-se nas movimentações diárias, mais e menos intensas, entre casas mais e menos distantes, com durações maiores e menores, cada uma das quais classificada e dinamizada singularmente de acordo com os modos pelos quais a comida puxa a prosa, que por sua vez puxa mais comida, e assim por diante. Por este rumo, a casa animada puxa gente ${ }^{10}$. Há entretanto diferenças importantes entre, de um lado, a circulação rotineira ligando as casas e, de outro lado, as ocasiões de visita. Ao contrário dos vizinhos, que estão 
cotidianamente presentes, o visitante é sempre alguém que fez um percurso não rotineiro para chegar até a casa visitada; vem de outras beiradas de rio. Ao mesmo tempo, as visitas costumam marcar laços de intimidade.

Há duas fases cíclicas em que as práticas de visita ocorrem com maior intensidade: o tempo das festas e o tempo da política. O primeiro é o das férias escolares, que coincidem com o tempo das festas de folia em homenagem aos Santos Reis. É quando muitos dos filhos, netos, sobrinhos e afilhados que deixaram de morar na localidade voltam para onde estão seus pais. Estes, com a casa cheia, reúnem a família e vão todos caminhar um par de horas para ir ao encontro dos foliões e, ao longo da caminhada, visitar os parentes das outras vizinhanças. Para evitar queixas, o grupo de visitantes busca passar no maior número de casas na vizinhança visitada. Em cada uma delas, comem e proseiam em quantidade, como se fosse a única casa visitada. É preciso calcular o quanto se come em cada casa para aguentar comer repetidamente, pois o de-comer oferecido pelos anfitriões é farto, e não se quer fazer desfeita a ninguém. O povo fica animado e muitos moradores da vizinhança se juntam aos visitantes para acompanhá-los no giro pelas casas da vizinhança. Deste modo, a circulação de visitas não só se intensifica como também amplia o seu alcance, colocando em relação não apenas famílias ou casas, mas vizinhanças inteiras, ou seja, todo um pessoal, incluindo aqueles que hoje moram nas capitais.

No tempo das festas, a grande quantidade de comida oferecida pelas diferentes casas que recebem uma mesma família em visita à vizinhança indica uma sutil disputa entre as casas visitadas. Percebe-se, por aí, o prestígio que o ato da visita concede à casa anfitriã. Mais do que isto, sabe-se que toda visita será transformada ela mesma em causo da visita. O visitante descreverá ao seu pessoal o causo do pessoal visitado, detalhando as diferenças entre as versões de cada casa. É assim que, no circuito de visitas, cada uma das casas expande suas perspectivas sobre o estado das coisas nos Buracos ou mesmo na região em geral.

Nas trocas envolvidas numa visita, a dádiva é oferecida pelo visitante, não pelo anfitrião, como seria na clássica cena do potlatch descrito por Marcel Mauss (2003 [1925]). Isto se expressa na forma ritualizada como, ao se despedir do visitante, o anfitrião agradece e depois pede escusas antecipadas: desculpe qualquer coisa; desculpe se alguma coisa não saiu do gosto seus. . . Em tom de brincadeira, os visitantes no momento de partirem cobram o que chamam jocosamente de pagamento. Nós espera vocês lá pra pagar a visita!, dizem. A retribuição pode levar meses ou anos para acontecer, e não serão explicitadas como pagamento ao que quer que seja. Afinal, a 
visita caracteriza-se justamente pela ausência de interesse, uma vez que se trata, por definição, de demonstrar consideração e bem-querer. Disto, não se deve inferir que a troca de palavras necessariamente conecta. Ao contrário, toda arte da prosa está em lidar com as possibilidades de ruptura. Daí a quantidade de pequenos cálculos que, como em um jogo especulativo sem fim, depende de um conjunto de elementos situacionais em constante mutação. Assim, a relação entre falantes, ouvintes e falados vai sendo posta em ação à medida que combinações de palavras, gestos e silêncios se sucedem.

Aos que foram fazer visita, as famílias vizinhas não se acanham em perguntar sobre os detalhes do passeio: quanto tempo ficaram numa ou noutra casa, o que comeram, o que prosearam? Ao se narrar uma vista, narram-se as relações com os visitados e também as que os visitados mapearam através dos causos contados e agora repetidos. A cada repetição, a versão de um causo se reforça ou se reconfigura, expandindo os efeitos das prosas realizadas nas casas visitadas para além de uma vizinhança, expandindo o poder da palavra dos anfitriões. O valor da visita reside portanto no próprio prestígio, ou na possibilidade de adquiri-lo por meio do causo da vista. Tal troca lembra-nos, neste sentido, o que Nancy Munn (1992) formulou a respeito das transações do Kula vistas da perspectiva da casa. A "fama” de um objeto trocado no circuito trobriandês depende de tudo o que se diz durante a negociação. Assim os objetos carregam o nome do dono, permitindo que o nome de certa pessoa “vá além”. O valor máximo da troca diz respeito a esta extensão espaço-tempo, que é a própria a memória - aquela que fornece os meios para "mover a mente do outro" e assim exercer poder.

Ao se trocarem as visitas, as casas se alternam nas posições de anfitriões e visitantes, donatários e doadores. Através da circulação hospitaleira, circula a posição de maior prestígio. Que o anfitrião mate uma galinha e ofereça também carne de gado ao visitante, que prepare um de-comer farto e variado, socando no pilão uma fina paçoca, amassando o biscoito frito para o lanche e fazendo assim a prosa do café da tarde render até o entardecer. Será uma valiosíssima recepção, mas o esforço preocupado dos anfitriões sugere que será sempre uma retribuição de segunda ordem diante da dádiva incomensurável da visita, graças à qual seu nome circula e a família acumula uma espécie de "poder". Como ocorre no caso das mulheres presenteadas ao chefe Guayaki (cf. Clastres, 2003 [1962]), a dádiva da visita buraqueira não pode ser retribuída com bens de valor de outra natureza; nenhum deles lhe é equiparável. Inspirando-nos na elaboração de Pierre Clastres, 
podemos imaginar que esta dívida impagável constitui a própria natureza do lugar de poder para os buraqueiros.

A valiosa relação estabelecida na visita é explorada pelos candidatos a vereador que fazem visita às casas da roça durante o que chamam o tempo da política, ou simplesmente a política. Durante o tempo da política ocorrido de quatro em quatro anos, na época das eleições para cargos municipais, os candidatos a prefeito e vereador empenham-se diariamente em visitar as comunidades para pedir voto. Os causos das visitas de político são neste sentido fonte tanto de manifestações de adesão política quanto de separações, rupturas, fofocas. A importância desses deslocamentos é tamanha que os candidatos com pouca verba de campanha precisam compartilhar entre eles um mesmo carro e um mesmo percurso para poderem dividir os custos com motorista e gasolina.

Se, no tempo das festas, a circulação de visitas se mantém através das gerações, consolidando os elos de intimidade e conhecimento de um povo, no tempo da política sabe-se que a circulação será interrompida assim que a política terminar. Se no tempo das festas a visita é desinteressada, motivada apenas pelo bem-querer dos parentes, no tempo da política a visita é sabidamente para pedir voto. Não à toa, ouvi algumas vezes, como piada, os buraqueiros denominarem dinheiro o papel que os políticos lhes distribuem, com seus retratos, partidos e números de candidatura, os chamados santinhos. Ao contrário de outros bens trocados, sabe-se que o dinheiro não costuma criar vínculos.

\section{A ação de visitação: valores em controvérsia}

Voltando ao episódio da ação de visitação, há de se destacar que a recusa em cobrar a visita, por parte dos parceiros locais, referia-se a visitantes específicos, aqueles com quem se desenrolavam conversas e aproximações, de dentro da casa. Esta especificidade chama atenção para um argumento sutil e entredito no gesto de recusa da cobrança em dinheiro: a disputa sobre os códigos e pressupostos engajados nas relações pessoais a serem estabelecidas no contexto do projeto. Neste sentido, antes de nos atermos mais detalhadamente ao episódio, vale abordar um acontecimento que o precedeu, e no qual o tema do dinheiro surgiu como alvo de debate sobre a viagem.

Havíamos previsto que os recursos da Caixa Econômica Federal pagariam aos viajantes um determinado valor em diárias, quantia necessária ao pagamento dos serviços turísticos prestados durante a viagem. Com dinheiro na mão, os parceiros locais se sentiriam verdadeiros turistas, pagando pelos serviços de hospedagem, passeios e 
comida. O problema foi que, por dificuldades de várias ordens e pouco acostumados aos trâmites bancários, parte dos viajantes não conseguiu sacar o dinheiro depositado em suas contas bancárias. As coordenadoras da ação decidiram então que pagariam as refeições e hospedagens, mas isto seria depois descontado das diárias a serem pagas aos viajantes no final da viagem, uma vez resolvidas as questões práticas individuais no saque do dinheiro.

Com isto, durante as visitas, os viajantes não precisaram pensar em dinheiro. $\mathrm{O}$ mal-estar foi gerado apenas quando, em meio à viagem, as coordenadoras expuseram os cálculos do que já havia sido gasto. Os viajantes se manifestaram, reclamaram por estarem atrelados a uma dívida pela qual não tinham tido responsabilidade. Não importava que o saldo desta dívida já estivesse garantido no próprio ato do empréstimo, o problema para os parceiros locais é que eles passavam pela posição de endividados sem terem optado por adquirir qualquer dívida. Não importava que a dívida já se sabia quitada ao final da viagem, sua posição de endividados, ao ser explicitada pelas coordenadoras, já era um dado daquela relação.

Quando uma das turismólogas descreveu detalhadamente nossa planilha de custos e fez as somas dos gastos individuais para descontar do valor das diárias, os participantes queixaram-se porque não iam receber o valor esperado inicialmente. Argumentavam que haviam deixado suas roças e animais a cargo de outros, a quem deveriam pagar, e agora se davam conta de que não lhes sobraria nada depois da viagem: saímos no prejuízo, diziam. Os custos pagos pelas turismólogas, afinal, haviam saído do controle deles, que talvez não tivessem aceitado pagar tanto por tal oferta de comida e hospedagem.

Paras as turismólogas, as queixas integravam um só problema: falta de comunicação. Em tom de desabafo, disse-me: "Esse pessoal de comunidade ainda não entendeu o valor deste projeto para eles, não entenderam que essa viagem deve ser um investimento para eles". Frustrada com as reclamações, chegou a questionar se o interesse das comunidades naquela viagem era só pelo dinheiro.

Pouco depois deste impasse, outra discussão sobre o valor da visita reconfigurou as posições sobre o que deveria ou não ser valorizado nos termos de investimento em dinheiro. Ao final dos cinco dias de visita aos moradores dos arredores das Cavernas do Peruaçu e da Terra Indígena Xakriabá, hospedamo-nos em um hotel na cidade de Januária, onde foi realizada uma dinâmica participativa. Os viajantes animaram-se. Falavam de si quando notavam mais semelhanças do que diferenças em relação ao modo de comer e de conversar dos Xakriabá. E achavam graça ao se perceberem na 
posição de turistas: percebiam-se sendo olhados por outros da maneira como eles mesmos costumavam ver seus outros. As turismólogas conduziam o diálogo, propondo uma avaliação dos roteiros de visitação e da qualidade de seus pontos atrativos. Em resposta, uma queixa geral foi sobre a qualidade variável da infraestrutura de recepção (instalações, gentileza e comida), que entretanto haviam custado o mesmo preço. O termo precificação foi então destacado pela turismóloga como um ponto importante. Como precificar?, perguntou ela.

Maria, uma das parceiras locais, contou então das duas ocasiões em que recebera turistas em sua casa. A primeira vez foi um homem que não quis pousar dentro de sua casa, preferiu dormir em uma barraca de camping que foi armada no quintal. Maria achou estranho, achou graça, mas concordou em fazer o trato: cobrou ao turista um valor pelo pouso no quintal e outro pela comida. A segunda visita de turista foi a de uma moça. Esta passou mais tempo com eles, dormiu de dentro da casa, proseou um bando, comeu com gosto o que a gente deu, além de ter passeado pela comunidade com Maria e seus familiares. Por fim, Maria não cobrou nada à jovem forasteira.

Ao ouvir o relato, a turismóloga balançou a cabeça negativamente. Isso é que não pode. Para que o turismo de base comunitária se estabeleça, é preciso estabelecer preços, fixar uma rede de pessoas e serviços com valores fixos, para que o dinheiro circule. A rede do turismo só se consolida se o dinheiro circular. No mesmo momento, Seu Zefino balançou a cabeça positivamente, mas o que disse foi: "eu me sinto muito mais valorizado se um turista chegar na minha casa, ficar uns dias lá, prosear com calma, do que um turista pagar cem reais e nem olhar na minha cara”. Diante da afirmação, fez-se um instante de silêncio entre as turismólogas, que em seguida voltaram a contestar, reafirmando a necessidade da precificação.

O debate ainda se desenrolou noutras falas que apenas reforçaram as posições conflitantes. A recusa dos parceiros locais em receber uma quantia em dinheiro, anunciada logo após terem se queixado pela falta do pagamento das diárias, pode ter sido uma sutil provocação, penso eu. A ironia, afinal, é uma das maneiras características com que esse povo da roça fala sobre temas espinhosos (cf. Carneiro, 2015a; 2015b). A recusa ao pagamento oferece-nos leituras diversas: servia para rebater a acusação de que estariam sendo interesseiros, ao mesmo tempo em que honrava o valor de suas condutas na generosidade desinteressada que se espera de qualquer anfitrião. Mas a atitude não se reduzia a estratégias, servia também à explicitação de um valor não financiável, defendido por argumentação acalorada. 


\section{Uma filosofia política sertaneja?}

Que valor inalienável algumas situações de visita sertaneja nos dão a ver?

Ao pensar as "entidades estranhamente paradoxais que são os valores, formas primitivas dos signos”, Patrice Maniglier (idem, p. 165) lembra que, para Lévi-Strauss, o signo é, por sua natureza, algo que circula. "Mauss julga ainda possível elaborar uma teoria sociológica do simbolismo, quando é preciso evidentemente buscar uma origem simbólica da sociedade" (Lévi-Strauss, [1950] 2003, p. 22 apud Maniglier, 2013, p. 166). Seguindo a formulação de Maniglier (2013, p. 164) a respeito da leitura que Lévi-Strauss fez da obra de Mauss, notamos que "[...] ser fiel à descoberta de Mauss sobre o caráter central da reciprocidade impunha ultrapassar a sociologia rumo a uma semiologia geral”. Toda troca é comunicação. Com isto, não é a troca que dá sentido às coisas, mas é porque damos sentidos às coisas que desejamos trocá-las. Similarmente, quando Marilyn Strathern (2006 [1988], p. 44-51) propõe que o estudo sobre a política melanésia seja entendido como costumam ser pensados os rituais - isto é, atividades constituídas de comportamento simbólico - não se trata de conceder anterioridade ao fenômeno simbólico, mas de assumir uma prerrogativa analítica: as coisas circulam porque têm valor e significado. Isto não significa negar a importância dos aspectos sociológicos na compreensão do que descrevemos, mas sim evitar pressuposições sobre as formas concretas que tais aspectos assumem.

Quais os significados das visitas nos diferentes circuitos de troca no Mosaico? O que estava sendo comparado, pelos parceiros locais, ao diferenciarem as trocas entre visitas, de um lado, e as realizadas entre visita e dinheiro, de outro?

Como espero ter mostrado até aqui, o gesto ritualizado das trocas de visita entre parentes faz circular querer-bem e fofoca, o que engaja variações de prestígio, conhecimento do povo e expansão da palavra - toda uma "política das reputações", diria Bailey (1971). Cada visita (e a circulação dos causos que ela mobiliza) atualiza/ reconfigura, à sua maneira, as relações entre casas, que se projetam no futuro graças às repercussões das conversas do presente na casa, com imaginações e cálculos sobre seus efeitos associativos e disruptivos, eloquentes e silenciosos. Há nisto uma concepção do "político" na qual a circulação de visitas (e de "poder") ganha centralidade $^{11}$. Podemos definir tais relações como "políticas", provisoriamente, com base na noção geral de que se trata das práticas individuais e/ou coletivas de composição de um “mundo comum” (cf. Latour, 2006, p. 366-367). Mas é importante que isto não se confunda com as maneiras recorrentes de se pensar a atividade política, 
como voltada à coesão do grupo. Afinal, como observaram Palmeira e Herédia (2010) sobre pequenas cidades do interior do Brasil, “política é divisão”. Ou, como dizem os buraqueiros, política é um trem feio; não pode misturar a pessoa [do candidato] com a política.

A noção do que venha a ser a "política" objetificada na investigação sobre o “poder” é uma questão antiga na antropologia. Como já lembraram Tania Stolze Lima e Marcio Goldman (2003, p. 13), o “poder” está no cerne da formação do pensamento antropológico. Este, nascido da Grande Divisão entre "nós” e os "outros", parece ter projetado, em tal divisão, a diferença entre contrato vs. status (cf. Henri Maine, 1861 apud Lima; Goldman, 2003). Assim, ambos têm a mesma função, subentendem a mesma concepção de poder: a manutenção da ordem e do equilíbrio sociais com base no modelo jurídico. A semelhança entre o contrato social e a teoria da dádiva maussiana já fora notada por Marshal Sahlins (1968, p. 8) quando este observava que, nos dois casos, a política surge como possibilidade de "escapar a uma condição de distribuição desordenada de forças”. No entanto, a novidade do contrato criado pela dádiva, escreve Sahlins sobre Mauss, é que esta troca não unifica as partes em um corpo solidário, um terceiro termo unificador das partes. Diversamente, a dádiva vincula os termos ao mesmo tempo em que os diferencia, vincula-os de forma segmentar. Reside nisto uma "filosofia política" própria ao "Ensaio sobre a Dádiva”.

Qual seria a forma assumida por esta relação entendida como "política” sem se confundir com o surgimento da "super-pessoa" do pacto social hobbesiano? Trata-se de um problema de ordem etnográfica. No Brasil, estudos produzidos a partir dos anos 1990 sob a ideia de uma "antropologia da política”, conforme o termo cunhado por Moacir Palmeira, propõem-se a evitar definições extrínsecas e buscar observar o que “do ponto de vista nativo" esteja relacionado a uma definição nativa da política. Em se tratando da "mesma língua", a tarefa ganha um desafio particular. Como atribuir alteridade a termos idênticos? O esforço é o de restituir “as dimensões êmicas das noções até as últimas consequências”, escreve Goldman (2006, p. 41), o que consiste em observar a um só tempo as abstrações produzidas pelas palavras nativas e as "modalidades concretas de sua atualização e utilização" (Idem). 
Ao conceber a ação de visitação do Projeto TBC-Mosaico, suas elaboradoras pensaram na tradicional visita a uma casa sertaneja: com boa prosa, o de-comer farto, quiçá uma dose de pinga, puxando causo. Se a visita turística não propulsiona a mesma circulação de causos, o importante é que isto não seja necessariamente verdade. Há alguns turistas especiais, como os exemplificados por D. Maria. Quando o turista visitante se deixa envolver pelo espaço da casa, aproximando-se dos anfitriões através da animação conjunta - - feita na troca de prosa puxada pela comensalidade, pelo compartilhamento de substâncias - há uma expansão das relações do dono da casa, uma expansão do seu “poder”, mesmo que a retribuição seja incerta. Ora, em certa medida, ela sempre o é. O importante é que se mantenha no horizonte como possibilidade, como signo da relação de compromisso entre anfitriões e visitantes.

O pagamento em dinheiro, efetuado pelo turista em troca do ofertado pelo anfitrião, nega a expansão das relações engajadas na casa. O preço pré-fixado da visita nega o valor latente das relações futuras, engajadas em um bom encontro nas casas. Além disto, o dinheiro pago pelo visitante-turista ao seu anfitrião-agricultor promove um desequilíbrio, um excesso desconfortável da dádiva da visita. O preço fixo - ou a precificação - cristalizaria assim a hierarquia entre duas formas coletivas dadas a priori: os parceos locais e os turistas. Ora, a importância da circulação de “poder”, como vimos, destaca-se no contraste entre as composições relacionais das visitas na vida cotidiana e no tempo da política, que configuram diferentes formas de disputar e fazer circular o prestígio.

Moacir Palmeira e Beatriz Herédia (2010), baseando-se em etnografias de diversas outras localidades do interior do Brasil, observaram a recorrência do termo "tempo da política"- ou simplesmente "a política”, e a definiram como um recorte temporal que é uma espécie de "ruptura do cotidiano", coincidindo com a época das campanhas políticas mas podendo a qualquer momento "invadir o cotidiano"12. É no intervalo do tempo da política que os posicionamentos pessoais se acirram ou se recriam de forma generalizada, em função das disputas políticas, quando se evidenciam e se consolidam os "lados", as "facções", promovendo rearranjos relacionais entre as famílias ou mesmo no interior delas. Gostaria aqui, por outro lado, de estimular nosso interesse sobre o risco inverso, o da invasão da política pelo cotidiano da casa. A partir do material etnográfico exposto aqui, parece-me que pensar essa "invasão" numa dupla direção pode nos abrir boas pistas sobre as essas diferentes composições relacionais Talvez, nesses termos, a pessoalização das relações políticas, à luz do que ocorre no tempo das festas, aponte para configurações diferentes da 
maneira como costumamos encará-las, sob a marca do "clientelismo".

Ao propor pensar uma "filosofia política da religiosidade afro-brasileira", José Carlos dos Anjos destacou "a pertinência de se pensar um outro equacionamento para o senso de equidade racial” (Anjos, 2008, p. 97). De modo similar, não se tratou aqui de investigar os mecanismos hierarquizantes já previstos, mas de abrirmo-nos às diferentes diferenças em jogo, nem sempre categorizadas, em geral apagadas por meio do uso de palavras tidas como autoevidentes. A "valorização cultural" é uma dessas palavras. Espécie de efeito inescapável do trabalho antropológico, ela é muitas vezes tida como justificativa positiva do nosso ofício. Ao percebermos e assumirmos que ela engaja, para usar os termos de Taussig (2010 [1980], p. 18), uma "pletora de significados contraditórios", podemos buscar os efeitos imprevistos de nossa própria ação. Quem sabe assim descreveremos formas de silenciamento e hierarquização mais sutis do que nossas boas intenções conseguem observar.

Recebido: 26/06/2019

Aprovado: 29/07/2019

Ana Carneiro Cerqueira possui graduação em Comunicação Social-Jornalismo na ECO-UFRJ; mestrado, doutorado e pós-doutorado em Antropologia Social no PPGAS-MN/UFRJ. Atualmente é profa. adjunta na UFSB, onde é credenciada no Programa de Pós-Graduação em Estado e Sociedade. Entre outras publicações, é autora dos livros O povo parente dos Buracos: sistema de Prosa e Mexida de Cozinha (E-Papers, 2015) e Que é feito de você, Mangueira (Vermelho Marinho, 2016), e coautora de Retrato da Repressão no Campo (MDA, 2010) e Giros etnográficos em Minas Gerais (7Letras, 2015). Seus principais temas de interesse são: Escrita etnográfica; Gênero, família e parentesco; Casa, corpo e cozinha; Antropologia da política; Estudos rurais. ORCID: 0000- 0003-1756-973. Contato: anacarcer@gmail.com 


\section{Notas}

1. Agradeço as sugestões dos/das pareceristas de Anuário Antropológico e as contribuições feitas por colegas a quem expus os (muitos) avatares deste texto. Pela oportunidade desses eventos, obrigada ao Seminário La Humanidad Compartida, na Universidad Nacional Autónoma de México (UNAM, 2017), coordenado por Isabel Martinez; Alejandro Fujigaki e Carlo Bonfiglioli; CosmoEncontros (UFF/Núcleo de Antropologia Cosmopolíticas, 2017), coordenado por Oiara Bonilla e Joana Miller; Seminário Pensando a Respeito... (CPDA/UFRRJ, 2017), coordenado por Eli de Lima e debatido por Andrey Cordeiro; XI RAM - Simpósio 8: La politica del transcurrir: imaginación antropológica y teoria etnográfica desde el sur (Montevideo, 2015), coordenado por Julieta Quirós, María Inés Fernández Álvarez e Julieta Gaztañaga. Agradeço ainda ao CNPq e à Faperj pelas bolsas de doutorado e pós-doutorado que permitiram esta pesquisa. Como de praxe, a responsabilidade pelo artigo é exclusivamente minha.

2. A pesquisa resultou em minha tese, defendida em 2010 no Programa de Pós-Graduação em Antropologia Social do Museu Nacional/UFRJ, sob orientação do Prof. Marcio Goldman, e publicada como livro intitulado O povo parente dos Buracos: sistema de prosa e mexida de cozinha (Carneiro, 2015).

3. O formato itálico será aqui utilizado para termos de língua estrangeira e para formulações nativas. Neste último caso, seja para atribuí-los a indivíduos específicos, seja para identificar fórmulas repetidas de modo generalizado no contexto etnográfico em análise. As aspas duplas indicarão conceitos e citações extraídas de publicações acadêmicas, podendo também ser usadas nos casos onde os termos, por força do uso, tornam-se chavões da bibliografia. Notem-se os limites desta categorização (o que justifica o uso excessivo do itálico), sobretudo, como é o caso aqui, quando os nativos publicam suas próprias análises e, por outro lado, a produção teórica circula e é instrumentalizada entre os sujeitos que se encontram, por força da análise, na posição de nativos. A situação complica-se ainda quando, conforme veremos, o conjunto daqueles que chamamos nativos inclui contextos discursivos de fontes distintas.

4. Mosaico é uma categoria jurídica do Sistema Nacional de Unidades de Conservação (SNUC, Lei 9.985/2000) que prevê a gestão integrada dos territórios, reunindo unidades de conservação e comunidades tradicionais. A participação da sociedade civil na gestão do Mosaico dá-se através de um Conselho Consultivo. Sobre a implementação do Plano de Desenvolvimento de Base Conservacionista do Mosaico Sertão Veredas - Peruaçu, conferir o documento elaborado pela Funatura (2008), disponível no link http://www.icmbio.gov.br/portal/images/stories/mosaicos/ plano-dtbc.pdf (acesso em: 26 jan. 2019). Mais informações podem ser obtidas em http: / / www.mosaicosvp.com.br. A cada dois anos, o plano passa por reformulações e os representantes do Conselho podem mudar. São 57 entidades: associações comunitárias, representantes de áreas protegidas, universidade e ONG's que atuam na região. Em 2018, entidades representantes do agronegócio foram incorporadas. Sobre a implantação do projeto de turismo ecocultural neste Mosaico, conferir Fontoura, Campos e Salgado (2018).

5. Municípios de Formoso, Arinos, Chapada Gaúcha, Urucuia, Cônego Marinho, Januária, Itacarambi, Bonito de Minas, São João das Missões, Miravânia e Manga (todos em MG). Atravessando o rio Carinhannha, município de Côcos (BA). As Terras Indígenas são:TI Xakriabá e TI Xakriabá Rancharia. As Unidades de Conservação são: APA Bacia do Rio Pandeiros; APA Cavernas do Peruaçu; 
APA Cochá Gibão; PE Mata Seca; PE Serra das Araras; PE Veredas do Peruaçu; PN Cavernas do Peruaçu; PN Grande Sertão Veredas; RDS Veredas do Acari; RVS Rio Pandeiros; RPPN's Aldeia, Arara Vermelha, Pacari e Porto Cajueiro. Incluem-se ainda dois Corredores Ecológicos: CE Vão dos Buracos e CE Rio do Ouro. Para mais informações, acessar https: / /mosaicosvp.com.br/.

6. O projeto de turismo de base comunitária teve a duração de cinco anos (2010-2015). O mesmo edital contemplou ainda o Projeto Extrativismo Vegetal Sustentável, também destinado ao Território Mosaico Sertão Veredas-Peruaçu. O fundo da Caixa concedeu R \$2,6 milhões para os dois projetos, que foram realizados no mesmo período; ambos executados por organizações sediadas em Chapada Gaúcha: o de extrativismo vegetal foi tocado pela Coop-Sertão Veredas, uma cooperativa de agricultores familiares que atua com beneficiamento e comercialização de produtos do cerrado. 7. Trata-se, em última análise, de pensar as práticas da casa como chave de reflexão etnográfica sobre as dinâmicas sociais do dinheiro, como já propôs Eugênia Motta (2014) ao seguir a abordagem de uma antropologia do dinheiro proposta por Federico Neiburg (2007). Sobre a observação das práticas cotidianas de resistência, importante mencionar o trabalho de James Scott (1976).

8. Minha tarefa na atividade era conhecer o projeto para mais tarde produzir sobre ele um texto de cunho jornalístico (disponível em https://mosaicosvp.com.br/diz-se-que/) e um vídeo institucional (disponível no link https: / / www.youtube.com/watch?v=MhapqoiydB4).

9. Vale mencionar a discussão sobre o tema da participação social, que envolve ampla produção teórica em diálogo com os efeitos práticos da aplicação de políticas públicas baseadas nesse princípio. Não caberá aqui aprofundar o tema. Para tanto, vale conferir, entre outros, Bezerra (2004); Dagnino (2004); Milani (2008) e Tatagiba (2003). Sobre os efeitos de captura observados em contextos de projetos de turismo ecocultural ou de base comunitária, ver Moraes, Mendonça e Pinheiro (2017); Telles (2016); Rodrigues, Irvinf e Drummond (2010).

9. Esta formulação ganhou força em um diálogo duradouro com colegas que se reuniram, a partir de 2012, ao notar que as maneiras de abordar e conceituar a movimentação, seja esta feita por pessoas, palavras, coisas ou outros seres, mostraram-se uma chave de leitura importante em diversas pesquisas. No âmbito do Nuap (Núcleo de Antropologia da Política), no PPGAS/MN/UFRJ, com uma bolsa de no pós-doutorado da Faperj, organizei, com Graziele Dainese e John Comerford, uma série de atividades, sob coordenação deste último (cf. Comerford; Carneiro; Dainese, 2015; Comerford, 2013; 2014; Carneiro; Dainese, 2015; Carneiro, 2014; 2015; 2017; Dainese, 2016), envolvendo um debate profícuo com diversos colegas (cf. Andriolli, 2011; Guedes, 2014; Pereira, 2011; Pissolato, 2007; Teixeira, 2014, entre outros). Recentemente, leituras como a de Ellis (1996) e Martínez (2014) apontaram-me boas pistas a serem exploradas a partir da noção de movimento. Sobre hospitalidade, ver Allerton (2012) e Shryock (2012).

10. A centralidade analítica do movimento do querer-bem é também uma opção por um certo viés sobre a centralidade da reciprocidade, tão fundamental como pouco explorada por Mauss, conforme observado por Eric Sabourin (2008), marcando campos e divisões entre os que se consideram herdeiros das reflexões maussianas.

11. Trata-se de um amplo conjunto de pesquisadores vinculados ao Núcleo de Antropologia da Política do PPGAS/MN/UFRJ. Sobre o movimento nas casas, vale conferir Alves (2016); Dainese (2011); Lagüens (2014). Sobre o tempo da política, Palmeira (2002). 


\section{Referências}

ANJOS, José Carlos dos. 2008. A filosofia política da religiosidade afro-brasileira como patrimônio cultural africano. Debates do NER, Porto Alegre, ano 9, n. 13, p. 77-96.

ALLERTON, Catherine. 2012. Making guests, making "liveliness": the transformative substances and sounds of Manggarai hospitality. Journal of the Royal Anthropological Institute, (N.S.), p. 49-62.

ALVES, Yara de Cássia. 2016 . A casa raiz e o voo de suas folhas: família, movimento e casa entre os moradores de Pinheiro-MG. Dissertação de mestrado, Universidade de São Paulo, São Paulo.

ANDRIOLLI, Carmen. 2011. Sob as vestes de Sertão Veredas, o Gerais. Mexer com criação no Sertão do IBAMA. Tese de doutorado, Programa de Pós-Graduação em Ciências Sociais, Universidade Estadual de Campinas , Campinas.

BAILEY, F. G. 2011. Gifts and Poison, In: BAILEY, F. G. Gifts and Poison. Oxford: Basil Blackwell, p. 1-25.

BASSO, Ellen. 1987. In favor of deceit. A study of tricksters in an Amazonian Society. Tucson: University of Texas Press.

BEZERRA, Marcos Otávio. 2004. Participação popular e conflitos de representação política: notas a partir de um caso de orçamento participativo, In: TEIXEIRA, Carla Costa; CHAVES, Christine de Alencar (orgs.). Tempos e espaços da política, p. 145-169.

BABCOCK-ABRAHAMS, Barbara. 1975. A tolerated margin of mess: The trickster and his tales reconsidered. Journal of the Folklore Institute, v. 11, n. 3.

CARNEIRO, Ana. 2017. "Mulher é trem ruim”. Revista Estudos Feministas, Florianópolis, v. 25, n. 2, p. 707-731.

CARNEIRO, Ana. 2015a. O povo Parente dos Buracos: sistema de prosa e mexida de cozinha. Rio de Janeiro: E-Papers.

CARNEIRO, Ana. 2015b. O sistema da mexida de cozinha: de que riem eles? In: CARNEIRO, Ana. Giros etnográficos em Minas Gerais: conflito, casa, comida, prosa, festa, política e o diabo. Rio de Janeiro: 7Letras.

CARNEIRO, Ana. 2014. Um causo, um povo, uma televisão: formas análogas. Mana, UFRJ, v. 20.

CARNEIRO, Ana; DAINESE, Graziele. 2015. Notas sobre diferenças e diferenciações etnográficas do movimento. Ruris, v. 9, n. 1, p. 143-166.

CARNEIRO DA CUNHA, Manuela. 2009. "Cultura” e cultura: conhecimentos tradicionais e direitos intelectuais. In: CARNEIRO DA CUNHA, Manuela. Cultura com aspas e outros ensaios. São Paulo: Cosac Naify, p. 311-375.

CLASTRES, Pierre. 2003[1962]. Troca e poder: filosofia da chefia indígena. In: CLASTRES, Pierre. Sociedade contra o Estado: pesquisas de antropologia política. São Paulo: Cosac Naify.

COMERFORD, John. 2014. Vigiar e narrar: sobre formas de observação, narração e julgamento de movimentações. Revista de Antropologia, São Paulo, USP, v. 57, n. 2.

COMERFORD, John. 2003. Como uma família: sociabilidade, territórios de parentesco e sindicalismo rural. Rio de Janeiro : Relume Dumará, p. 25-139.

COMEFORD, Jonh; CARNEIRO, Ana; DAINESE, Graziele (orgs.). 2015. Giros etnográficos em Minas Gerais: casa, conflito, comida, prosa, política, festa e o diabo. Rio de Janeiro: 7Letras. 
DAGNINO, Evelina. 2004. Construção democrática, neoliberalismo e participação: os dilemas da confluência perversa. Política \& Sociedade, n. 5, p. 139-164.

DAINESE, Graziele. 2016. Movimento e animação das festas, visitas, andanças e chegadas. Mana v. 22, n. 3, p. 641-669.

DAINESE, Graziele. 2011. Chegar ao cerrado mineiro: hospitalidade, política e paixões. Tese de Doutorado, Programa de Pós-Graduação em Antropologia Social, Museu Nacional, Universidade Federal do Rio de Janeiro, Rio de Janeiro.

DELEUZE, Gilles; GUATTARI, Felix. 1980. Mille Plateaux. Capitalisme et Schizophrénie 2. Paris: Minuit.

DELEUZE, Gilles; GUATTARI, Félix. 1968. Différence et répétition. Paris : PUF.

DUMANS GUEDES, André. 2013. O trecho, as mães e os papéis: etnografia de movimentos e durações no Norte de Goiás. São Paulo: Garamond.

ELLIS, Rebecca. 1996. A taste for movement: an exploration of the social ethics of the tsimanes of lowland Bolivia. St. Andrews: University of St. Andrews.

FONTOURA, Ana Gabriela da Cruz; CAMPOS, Damiana Souza; SALGADO, Herbert Canela. 2018. Turismo comunitário, território imaginado e democracia: complexidade territorial, espacialização do turismo no Mosaico SertãoVeredas-Peruaçu e os desafios da sociobiodiversidade sertaneja no espaço das viagens contemporâneas. Anais do VI Congresso em Desenvolvimento Social, PPGDS/Unimontes.

GOLDMAN, Marcio. 2006. Como funciona a democracia: uma teoria etnográfica da política. Rio de janeiro: 7Letras.

GUATTARI, Félix. 1996. Cultura: um conceito reacionário? In: ROLNIK, Sueli; GUATTARI, Felix (orgs.). Micropolítica: cartografias do desejo. Rio de Janeiro: Petrópolis, p. 11-25.

INSTITUTO ROSA E SERTÃO. Construindo roteiros turísticos de forma participativa: desafios no Mosaico SertãoVeredas - Peruaçu, mimeo., s/d.

LATOUR, Bruno. 2006. Changer de société, refaire de la sociologie. Paris : Éditions de la Découverte. LÉVI-STRAUSS, Claude. 2003 [1950]. Introdução à obra de Marcel Mauss. In: LÉVI-STRAUSS, Claude. Sociologia e antropologia, Tradução Paulo Neves, São Paulo: Cosac \& Naify.

LAGÜENS, João. 2014. Casa e política: amizade, alianças e interesses. Tese de Doutorado, Programa de Pós-Graduação em Antropologia Social, Museu Nacional, Universidade Federal do Rio de Janeiro, Rio de Janeiro.

LIMA, Tânia Stolze; GOLDMAN, Marcio. 2003. Prefácio. In: CLASTRES, Pierre. A sociedade contra o Estado: pesquisas de antropologia política. São Paulo: Cosac Naify.

MANIGLIER, Patrice. 2013. De Mauss a Claude Lévi-Strauss - cinquenta anos depois: por uma ontologia Maori. Cadernos de campo, São Paulo, n. 22, p. 163-179.

MARTÍNEZ, Isabel. 2014. El camino rarámuri como concepto: traducción y reversibilidad como potencia teórica. Ruta Antropológica I, año 1, n. 1, Instituto de Investigaciones Antropológicas-UNAM, México, p. 49-60.

MARTINS, José de Souza. 1996. O tempo da fronteira: retorno à controvérsia sobre o tempo histórico da frente de expansão e da frente pioneira. Tempo social - Rev. Sociol. USP, São Paulo, v. 8, n. 1, p. 25-70. MAUSS, Marcel. 2003 [1925]. Ensaio sobre a dádiva, em Sociologia e antropologia, Tradução Paulo Neves, 
São Paulo: Cosac \& Naify, p. 183-314.

MORAES, Edilain Albertino; Mendonça, Teresa Cristina e Pinheiro, Carolina Vasconcelos. 2017. Trilhando o turismo de base comunitária em Minas: um novo caminho das Gerais. Cultur - Revista de Cultura e Turismo, v. 11, n. 1 .

MOTTA, Eugênia. 2014. Houses and economy in the favela. Vibrant, v. 11, n. 1, p. 118-158.

MUNN, Nancy. 1992. The fame of Gawa. A symbolic study of value transformation in Massim society. Durham: Duke University Press Books.

MUSUMECI, Leonarda. 1988. O mito da terra liberta (colonização espontânea, campesinato e patronagem na Amazônia Oriental. São Paulo: Vértice; ANPOCS.

NEIBURG, Federico. 2007. As moedas doentes, os números públicos e a antropologia do dinheiro. Mana, v. 8 , n. 1, p. 119-151.

PALMEIRA, Moacir. 2002. Política e tempo: nota exploratória. In: PEIRANO, Mariza (org.). O dito e o feito: ensaios de antropologia dos rituais. Rio de Janeiro: Relume-Dumará, p. 171-178.

PALMEIRA, Moacir; HEREDIA, Beatriz. 2010. Os comícios e as políticas de facções. In: PALMEIRA, Moacir; HEREDIA, Beatriz. Política ambígua. Rio de Janeiro: Relume-Dumará; Nuap, p. $27-81$.

PALMEIRA, Moacir; HEREDIA, Beatriz. 1997. Política ambígua, In:BIRMAN, P., NOVAES, R. e SAMIRA, C. (orgs.). O mal à brasileira. Rio de Janeiro: EdUERJ.

PAZZARELLI, Francisco. 2016. La equivocación de las cocinas: humos, humores y otros excesos em los Andes meridionales, em Revista de Antropologia da USP, v. 59, n. 3, p. 49-72.

PEREIRA, Luzimar. 2018. O diabo da dúvida: histórias de pacto com o demônio no norte e noroeste de Minas Gerais. Revista del Museo de Antropología, v. 11, Suplemento Especial 1, p. 25-34, 2018.

PEREIRA, Luzimar. 2011. Os giros do sagrado: um estudo etnográfico sobre as folias em Urucuia - Minas Gerais. Rio de Janeiro: Editora 7Letras.

PERUTTI, Daniela. 2018. Em cada casa, uma carta: políticas públicas e modos de habitar no quilombo Família Magalhães (GO). Revista Tessituras, v. 6, n. 2, p. 46-74.

PISSOLATO, Elizabeth. 2007. A duração da pessoa. Mobilidade, parentesco e xamanismo mbya (Guarani). São Paulo: Editora da Unesp.

RIBEIRO, Eduardo Magalhães; GALIZONI, Flávia Maria. 2007. A arte da catira: negócios e reprodução familiar de sitiantes mineiros. Revista Brasileira de Ciências Sociais, v. 22, n. 64, p. 65-192.

RODRIGUES, Camila; IRVING, Marta de A.; DRUMMOND, José Augusto. 2010. A valoração das propriedades estéticas e recreativas da biodiversidade e o turismo em parques nacionais. Anais do V Encontro Nacional da Anppas. Florianópolis, 4 a 7 de outubro.

SABOURIN, Eric. 2008. Marcel Mauss: da dádiva à questão da reciprocidade. Revista Brasileira de Ciências Sociais, v. 23, n. 66, p. 131-138.

SAHLINS, Marshall. 1968. Philosophie politique de “''essai sur le don". L'Homme, t. 8, n. 4, p. 5-17. SCOTT, James C. 1976. The moral economy of the peasant: rebellion and subsistence in southeast Asia. New Haven: Yale University Press.

SHRYOCK, Andrew. 2012. Breaking hospitality apart: bad hosts, bad guests, and the problem of sovereignty. Journal of the Royal Anthropological Institute (N.S.), p. S20-S33. 
STRATHERN, Marilyn. 2006 [1988] O gênero da dádiva: problemas com as mulheres e problemas com a sociedade melanésia, tradução AndréVillalobos, Campinas: Editora da Unicamp.

STRATHERN, Marilyn. 1998. Novas formas econômicas: um relato das Terras Altas da Papua-Nova Guiné. Mana, v. 4, n. 1, p. 109-139

TATAGIBA, Luciana. 2003. Participação, cultura política e modelos de gestão: a democracia gerencial e suas ambivalências. Tese de doutoramento, Universidade Estadual de Campinas, Campinas.

TAUSSIG, Michael. 2010 [1980]. O diabo e o fetichismo da mercadoria na América do Sul; tradução Priscila Santos da Costa, São Paulo: Ed. UNESP.

TEIXEIRA, Jorge Luan. 2014. Na terra dos outros: mobilidade, trabalho e parentesco entre os moradores do Sertão do Inhamuns (CE). Dissertação de Mestrado, Programa de Pós- Graduação em Antropologia Social, Museu Nacional, Universidade Federal do Rio de Janeiro, Rio de Janeiro.

TELLES DE MENEZES, Adriano. 2016. O Mosaico SertãoVeredas - Peruaçu: a ressignificação de Grande Sertão:Veredas pelo turismo literário. Dissertação de Mestrado, Mestrado profissional em turismo, Universidade de Brasília, Brasília.

VIVEIROS DE CASTRO, Eduardo. 2004. Perspectival Anthropology and the Method of Controlled Equivocation. Tipití: Journal of the Society for the Anthropology of Lowland South America, v. 2, n. 1. 
Resumo: Em função de um episódio ocorrido durante uma ação de visitação promovida, em 2015, pelo Projeto deTurismo Ecocultural de Base Comunitária do Território Mosaico Sertão Veredas - Peruaçu, recupero dados coletados por uma pesquisa etnográfica realizada, entre 2006 e 2009, com o Povo dos Buracos, abrangido pelo projeto. No episódio, alguns agricultores recusavam-se a cobrar dinheiro a turistas que visitariam suas casas. Contrariamente, as coordenadoras da ação diziam ser necessário precificar a estadia dos turistas nas casas dos agricultores para que estes conseguissem gerar renda. Que espécie de relação outra com os turistas poderia ser desejada se não a da troca mercantil? Não se trata aqui de estabelecer externalidade entre dois mundos supostamente opostos, um dos laços comunitários, outro do mercado. O objetivo é indagar sobre como certas composições relacionais assumem maneiras específicas de lidar com o dinheiro. Por este caminho, ao final do artigo exploro a ideia de uma "filosofia política” presente nas práticas sertanejas de visita.

Palavras-chave: Hospitalidade; Dinheiro; Antropologia da política; Turismo de base comunitária; Território Mosaico Sertão Veredas - Peruaçu.
Abstract: This article addresses an incident that took place during a visitation action promoted in 2015 by the project "Community Based Eco-cultural Tourism in the Sertão Veredas - Peruaçu Protected Area Mosaic" to the Povo dos Buracos, a traditional community, situated in the protected area, which draws on data collected during an ethnographic study conducted between 2006 and 2009. During the visitation, some farmers refused to charge the tourists for staying in their homes. The visitation coordinators, however, insisted that it was necessary to price the tourists' stay to generate income for the farmers. Which relationship could the farmers wish to establish with the tourists that is anything other than commercial? The aim of this article is not to place two supposedly external worlds - that of community ties and that of the market - in opposition to each other, but rather explore how certain relational compositions have their own specific ways of dealing with money. In the same vein, at the end of the article I explore the idea that "political philosophy" is present in this traditional community's visiting practices.

Keywords: Hospitality; Money; Politics; Community Based Tourism; Sertão Veredas - Peruaçu Protected Area Mosaic. 